\title{
KUALITAS HIDUP PENDERITA DIABETES MELLITUS DAN DETERMINANNYA DI KABUPATEN GORONTALO
}

\author{
Quality of Life of Diabetes Melitus and Determinants in Gorontalo District
}

\author{
Zul Adhayani Arda, ${ }^{1}$ Sunarti Hanapi, ${ }^{2}$ Yeni Paramata, ${ }^{3}$ Abdul Rahmat Ngobuto ${ }^{4}$ \\ Fakultas Kesehatan Masyarakat, Universitas Gorontalo
}

Korespondensi: niarda87@gmail.com

\begin{abstract}
ABSTRAK
Kualitas hidup adalah penilaian subjektif seseorang melalui pengalaman terhadap sesuatu yang telah dialaminya dalam kehidupan. Salah satu yang banyak menyebabkan penurunan kualitas hidup masyarakat adalah penyakit, seperti Diabetes Melitus (DM) yang banyak diderita oleh masarakat saat ini. Penelitian ini bertujuan untuk mengetahui determinan kualitas hidup pada penderita Diabetes Melitus di Kabupaten Gorontalo. Jenis penelitian yang digunakan adalah observasional analitik dengan desain penelitian cross sectional. Sampel dalam penelitian ini adalah sebanyak 313 responden, yang dipilih dengan teknik stratified random sampling. Analisa data secara univariat dan bivariat. Penelitian ini dilaksanakan pada bulan Desember sampai Januari 2019. Hasil penelitian univariat menunjukkan proporsi responden dengan kualitas hidup tinggi sebesar $44,7 \%$. Hasil bivariat menunjukkan adanya hubungan tingkat pendidikan $(\mathrm{p}=0.000)$, status pekerjaan $(\mathrm{p}=0.000)$, status ekonomi $(\mathrm{p}=0.000)$ dan lama menderita $(\mathrm{p}=0.000)$ dengan kualitas hidup penderita diabetes mellitus. Tidak ada hubungan umur $(\mathrm{p}=0.676)$ dengan kualitas hidup penderita diabetes mellitus. Untuk itu, diharapkan kepada petugas kesehatan dan masyarakat agar lebih meningkatkan perhatian pada penderita Diabetes Melitus terutama bagi yang telah cukup lama menderita DM.
\end{abstract}

Kata kunci: Kualitas hidup, determinan, diabetes melitus.

\section{ABSTRACT}

Quality of life is a person's subjective assessment through experience of something they have been in life. One of causes decreasing the quality of life of people is a disease, such as Diabetes Mellitus (DM), which is common in today's society. This study aims to determine the determinants of quality of life in people with Diabetes Mellitus in Gorontalo District. This type of research is analytic observational with cross sectional research design. The sample in this study were 313 respondents selected using using stratified random sampling. The data werw analyzed using univariate and bivariate analysis. This research was conducted from December 2018 to January 2019. The results of the univariate research showed that the proportion of respondents with a high quality of life was $44.7 \%$. The bivariate results showed a relationship between education level $(p=0.000)$, employment status $(p=0.000)$, economic status $(p=0.000)$ and duration of suffering $(p=0.000)$ with the quality of life of people with diabetes mellitus. . There is no relationship between age $(p=0.676)$ with the quality of life of people with diabetes mellitus. For this reason, it is hoped that health workers and the community will increase their attention to diabetes mellitus sufferers, especially those who have suffered from diabetes for a long time.

Keywords: Quality of life, determinant, diabetes mellitus. 


\section{PENDAHULUAN}

Diabetes mellitus (DM) merupakan penyakit gangguan metabolik menahun akibat pankreas yang tidak memproduksi cukup insulin atau tubuh tidak dapat menggunakan insulin secara efektif. Insulin merupakan hormon yang memproduksi kadar gula darah. Akibatnya terjadi peningkatan konsentrasi glukosa di dalam darah (Hiperglikemia) (Infodatin, 2014).

World Health Organization (WHO) memperkirakan secara global terdapat 422 juta orang yang penderita DM pada tahun 2014, jauh meningkat dibandingkan pada tahun 1980 dengan jumlah penderita hanya 108 juta orang. Peningkatan kasus ini juga terkait dengan peningkatan faktor risiko DM seperti kelebihan berat badan atau obesitas. Selama dekade terakhir, prevalensi diabetes telah meningkat lebih cepat di negara-negara berpenghasilan rendah dan menengah diabndingkan dengan negara-negara berpenghasilan tinggi (WHO, 2016). International Diabetes Federation (IDF) memperkirakan bahwa setiap 7 detik satu orang meninggal karena diabetes dan 4,9 juta orang meninggal tiap tahunnya. Setengah dari kematian akibat DM terjadi pada umur dibawah 60 tahun (IDF, 2015).

Prevalensi diabetes di Indonesia pada penduduk umur $\geq 15$ tahun berdasarkan wawancara yang terdiagnosis dokter sebesar 1,5\% pada tahun 2013 dan meningkat menjadi 2\% pada tahun 2018. Sedangkan prevalensi diabetes berdasarkan pemeriksaan darah pada penduduk umur $\geq 15$ tahun pada tahun 2013 sebesar 6,9\% dan pada tahun 2018 prevalensi diabetes meningkat menjadi $8,5 \%$. Untuk peringkat provinsi berdasarkan prevalensi DM, yang menduduki urutan pertama adalah DKI Jakarta dengan prevalensi kasus 3,4\% dan yang menempati urutan terendah yaitu Provinsi NTT dengan prevalensi 0,9\%. Sedangkan Provinsi Gorontalo menempati posisi ke delapan dengan prevalensi $>2 \%$ (Riskesdas, 2018).

Data Dinas Kesehatan Provinsi Gorontalo dalam 2 tahun terakhir dari tahun 2013 ke tahun 2014 tercatat jumlah total penderita diabetes melitus pada kasus baru, kasus lama dan kematian akibat diabetes melitus mengalami peningkatan (Dinas Kesehatan Provinsi Gorontalo, 2014). Berdasarkan data Dinas Kesehatan Kabupaten Gorontalo tahun 2015 sampai 2017 mengalami peningkatan kasus yang sangat signifikan yaitu 977 kasus pada tahun 2015, 1250 kasus pada tahun 2016, dan terjadi peningkatan kasus ayng signifikan pada tahun 2017 menjadi 3072 kasus (Dinas Kesehatan Kabupaten Gorontalo, 2017).

Penelitian ini bertujuan untuk mengetahui faktor determinan kualitas hidup penderita diabetes mellitus di beberapa Puskesmas di Kabupaten Gorontalo.

\section{BAHAN DAN METODE}

Jenis penelitian adalah observasional analitik dengan rancangan cross sectional study. Penelitian ini dilakukan di beberapa wilayah kerja puskesmas di Kabupaten 
http://journal.unpacti.ac.id/index.php/JPP

Gorontalo yaitu Puskesmas Pulubala,

Puskesmas Limboto, Puskesmas Dungaliyo,

Puskesmas Tabongo dan Puskesmas Batudaa.

Populasi dalam penelitian ini adalah seluruh penderita Diabetes Melitus tipe 2 dari 5 wilayah kerja puskesmas tersebut yaitu sebanyak 1673 penderita, sedangkan sampel yang diambil sebanyak 313 responden. Teknik pengambilan sampel yang digunakan adalah stratified random sampling. Data dikumpulkan melalui wawancara langsung menggunakan kuesioner yang disusun sendiri untuk mengukur variabel independen dan kuesioner WHOQOL-BREF untuk mengukur variabel dependen. Analisis data dilakukan secara univariat dan bivariat menggunakan uji chi square. Data yang telah diolah kemudian disajikan dalam bentuk tabel disertai dengan penjelasan.

\section{HASIL}

Univariat

Karakteristik responden dalam penelitian ini berdasarkan distribusi umur, jenis kelamin, pendidikan dan wilayah kerja puskesmas (Tabel.1) menunjukkan bahwa responden paling banyak berasal dari kelompok umur dewasa $(73,5 \%)$ dan berjenis kelamin perempuan (71,6\%). Dari kategori tingkat pendidikan, paling banyak responden memiliki tingkat pendidikan sampai Sekolah Dasar (SD) dengan persentase 30\%. Untuk wilayah tempat tinggal. Sebanyak 105 responden $(33,5 \%)$ berasal dari wilayah kerja Puskesmas Limboto.

\section{Bivariat}

Hasil analisis bivariat yang menilai hubungan variabel independen (umur, tingkat pendidikan, status pekerjaan, status ekonomi dan lama menderita) dengan variabel dependen (kualitas hidup penderita Diabetes Melitus) dilihat pada Tabel 2.

Tabel 1.

\section{Karaktersitik Responden Penderita Diabetes Melitus di Kabupaten Gorontalo}

\begin{tabular}{lcc}
\hline Karaktersitik & \multicolumn{2}{c}{ Jumlah } \\
\cline { 2 - 3 } Responden & n & \% \\
\hline Umur & & \\
Dewasa & 230 & 73,5 \\
Lansia & 83 & 26,5 \\
Jenis Kelamin & & \\
Laki-laki & 89 & 28,4 \\
Perempuan & 224 & 71,6 \\
Pendidikan & & \\
Tidak tamat SD & 52 & 16,6 \\
SD & 94 & 30,0 \\
SLTP & 56 & 17,9 \\
SLTA & 76 & 24,3 \\
S1/S2/S3 & 35 & 11,2 \\
Puskesmas & & \\
Pulubala & 44 & 14,1 \\
Limboto & 105 & 33,5 \\
Dungaliyo & 70 & 22,4 \\
Tabongo & 50 & 16,0 \\
Batudaa & 44 & 14,1 \\
\hline
\end{tabular}

Sumber: Data Primer, 2019

\section{PEMBAHASAN \\ Umur}

Diabetes mellitus merupakan penyakit yang sering muncul karena kegagalan metabolism akibat semakin bertambahnya umur. Sehingga semakin tua umur seseorang maka akan semakin rentan untuk terkena penyakit diabetes mellitus. Penderita DM yang mampu mencegah terjadinya komplikasi 
diyakini mempunyai kualitas hidup yang tinggi

(Meidikiyanti dan Wahyuni, 2017)

Responden dari kelompok umur dewasa (18-59 tahun) umumnya memiliki kualitas hidup yang rendah $(54,3 \%)$. Sama halnya dengan responden dari kelompok umur lansia ( $\geq 60$ tahun) yang paling banyak dengan kulaitas hidup rendah $(57,8 \%)$. Hasil uji chi square menunjukkan nilai $\mathrm{p}=0,676$, artinya tidak ada hubungan yang signifikan antara umur dengan kualitas hidup diabetes mellitus di Kabupaten Gorontalo. Hasil penelitian ini sejalan dengan penelitian yang dilakukan oleh Wahyuni, dkk (2014), dimana diperoleh tidak ada hubungan signifikan antara umur dengan kualitas hidup diabetes mellitus tipe 2 dengan nilai persentase pada penelitian tersebut menunjukkan bahwa persentase terbesar dari responden yang mempunyai nilai kualitas hidup tinggi adalah responden pada kelompok umur lansia $(65,9 \%)$.

Usia dewasa cenderung berpikir bahwa penyakit degeneratif seperti diabetes melitus hanya menimpa orang yang berusia lanjut, sehingga tidak terlalu memperhatikan pola konsumsi atau aktivitas fisik yang merupakan fantor risiko DM. Hal ini menjadi peneyebab rendahnya kualitas hidup pada orang dewasa karena ketidaksiapan dalam menghadapi risiko penyakit Diabetes Melitus. Namun, pada penelitian ini juga terdapat responden lansia yang kualitas hidupnya rendah. Hal ini mungkin dipengaruhi oleh kondisi fisik, intelektual dan psikologis yang semakin menurun seiring dengan semakin bertambahnya usia.

Tabel 2.

Analisis Determinan Kualitas Hidup Penderita Diabetes Melitus Di Kabupaten Gorontalo

\begin{tabular}{|c|c|c|c|c|c|c|c|}
\hline \multirow{3}{*}{ Variabel } & \multicolumn{4}{|c|}{ Kualitas Hidup } & \multirow{2}{*}{\multicolumn{2}{|c|}{ Total }} & \multirow{3}{*}{ P Value } \\
\hline & \multicolumn{2}{|c|}{ Rendah } & \multicolumn{2}{|c|}{ Tinggi } & & & \\
\hline & $\mathbf{n}$ & $\%$ & $\mathbf{n}$ & $\%$ & $\mathbf{n}$ & $\%$ & \\
\hline \multicolumn{8}{|l|}{ Umur } \\
\hline Dewasa & 125 & 54,3 & 105 & 45,7 & 230 & 100 & 0,676 \\
\hline Lansia & 48 & 57,8 & 35 & 42,2 & 83 & 100 & \\
\hline \multicolumn{8}{|c|}{ Tingkat Pendidikan } \\
\hline Rendah & 132 & 65,3 & 70 & 34,7 & 202 & 100 & 0,000 \\
\hline Tinggi & 41 & 36,9 & 70 & 63,1 & 111 & 100 & \\
\hline \multicolumn{8}{|l|}{ Status Pekerjaan } \\
\hline Bekerja & 45 & 40,5 & 66 & 59,5 & 111 & 100 & 0,000 \\
\hline Tidak Bekerja & 128 & 63,4 & 74 & 36,6 & 202 & 100 & \\
\hline \multicolumn{8}{|l|}{ Status Ekonomi } \\
\hline Tinggi & 12 & 21,4 & 44 & 78,6 & 56 & 100 & 0,000 \\
\hline Rendah & 161 & 62,6 & 96 & 37,4 & 257 & 100 & \\
\hline \multicolumn{8}{|l|}{ Lama Menderita } \\
\hline Baru & 163 & 61,5 & 102 & 38,5 & 265 & 100 & 0,000 \\
\hline Lama & 10 & 20,8 & 38 & 79,2 & 48 & 100 & \\
\hline
\end{tabular}

Sumber: Data Primer, 2019 


\section{Tingkat Pendidikan}

Pendidikan merupakan tingkatan pendidikan secara formal yang diterima oleh seseorang dalam bangku sekolah, mulai dari sekolah dasar sampai perguruan tinggi (Lara dan Hidajah, 2016). Seamkin tinggi pendidikan seseorang maka diharapkan akan semakin baik pula kualitas hidupnya, karena akan memiliki pengalaman yang cukup dalam manajemen diri termasuk dalam hal mencari perawatan dan pengobatan terhadap penyakit yang diderita (Siwiutami, 2017)

Responden dengan tingkat pendidikan rendah, 65,3\% memiliki kualitas hidup yang rendah. Sedangkan responden dengan tingkat pendidikan tinggi, $63,1 \%$ memiliki kualitas hidup tinggi. Hasil uji chi square menunjukkan nilai $\mathrm{p}=0,000$ yang berarti ada hubungan yang signifikan antara tingkat pendidikan dengan kualitas hidup diabetes mellitus. Penelitian ini sejalan dengan penelitian yang dilakukan oleh Retnowati dan Satyabakti (2015), dimana diperoleh hasil penelitian terdapat hubungan yang signifikan antara tingkat pendidikan dan kulaitas hidup penderita diabetes mellitus tipe 2 dengan nilai $\mathrm{p}=0,039$.

Seseorang yang memiliki pendidikan tinggi akan mencari informasi secara mandiri tentang cara meningkatkan kualitas hidup seperti informasi manajemen perawatan dan pengobatan DM. Sementara orang yang berpendidikan rendah cenderung berdiam diri dan kurang aktif dalam mencari informasi tentang manajemen perawatan, pengobatan, dan peningkatan kualitas hidup. Dalam penelitian ini juga terdapat responden yang berpendidikan tinggi namun kualitas hidupnya rendah. Dari hasil wawancara dengan responden diperoleh informasi bahwa kondisi ekonomi yang rendah cukup berpengaruh terhadap peningkatan kualitas hidup.

\section{Status Pekerjaan}

Pekerjaan merupakan jenis kedudukan seseorang dalam melakukan pekerjaan di suatu unit usaha atau kegiatan (BPS, 2018). Dalam penelitian ini responden dengan status bekerja umumnya memiliki kualitas hidup yang tinggi (59,5\%). Sedangkan responden dengan status tidak bekerja umumnya memiliki kualitas hidup yang rendah $(63,4 \%)$. Hasil uji chi square menunjukkan nilai $\mathrm{p}=0,000$ yang berarti ada hubungan yang signifikan antara tingkat pendidikan dengan kualitas hidup penderita diabetes mellitus. Penelitian ini didukung oleh hasil peenlitian Sari, dkk (2011) yang menunjukkan bahwa ada hubungan yang signifikan antara status pekerjaan dengan kualitas hidup penderita diabetes mellitus, dimana pasien yang bekerja memiliki kualitas hidup yang lebih tinggi dibanding pasien yang tidak bekerja.

Responden yang memiliki status bekerja baik itu PNS, pegawai swasta, wiraswasta ataupun petani maka akan memiliki banyak aktivitas fisik yang dilakukan di luar rumah. Berbeda dengan responden dengan status tidak berkeja akan menghabiskan sebagian waktunya di dalam rumah dan cenderung kurang melakukan aktivitas fisik. Hal inilah yang menjadi alasan responden yang 
bekerja memiliki kualitas hidup yang lebih tinggi.

\section{Status Ekonomi}

Responden dengan status ekonomi tinggi paling banyak memiliki kualitas hidup yang tinggi juga (78,6\%). Sebaliknya responden dengan status ekonomi rendah juga paling banyak memiliki status ekonomi yang rendah (62,6\%). Hasil uji chi square menunjukkan nilai $\mathrm{p}=0,000$ yang berarti ada hubungan yang signifikan antara status ekonomi dengan kualitas hidup penderita diabetes mellitus. Penelitian ini sejalan dengan penelitian yang dilakukan oleh Retnowati dan Satyabakti (2015) yang memperoleh hasil bahwa terdapat hubungan yang signifikan antara pendapatan dengan kualitas hidup penderita diabetes mellitus tipe 2 , dengan nilai $\mathrm{p}=0,034$.

Status ekonomi dalam penelitian ini diukur berdasarkan pendapatan keluarga yang diperoleh selama sebulan kemudian dibandingkan dengan Upah Minimum Provinsi (UMP) Gorontalo. Responden yang memiliki status ekonomi tinggi akan lebih mudah melakukan manajemen perawatan terhadap diabetes mellitus karena memiliki dukungan financial yang cukup dibanding orang yang status ekonomi rendah. Selain dukungan financial, adanya pengetahuan yang cukup tentang perawatan penyakit DM juga menjadi variabel pendukung dalam meningkatkan kualitas hidup.

\section{Lama Menderita}

Responden yang telah lama menderita
DM ( $\geq 10$ tahun) sebanyak 79,2\% memiliki kualitas hidup yang tinggi. Sedangkan responden yang baru menderita DM $(<10$ tahun) sebnyak $61,5 \%$ memiliki kualitas hidup yang rendah. Hasil uji chi square menunjukkan nilai $\mathrm{p}=0,000$ yang berarti ada hubungan yang signifikan antara lama menderita dengan kualitas hidup diabetes mellitus. Penelitian ini sesuai dengan penelitian yang dilakukan oleh Ningtyas, dkk (2013), yang menunjukkan bahwa ada hubungan yang signifikan antara lama menderita DM dengan kualitas hidup penderita diabetes mellitus dengan nilai $\mathrm{p}=$ 0,048 (nilai $\mathrm{OR}=3,8$ ). Namun penelitian ini berbanding terbalik dengan penelitian yang dilakukan Setiyorini (2017) dimana diperoleh bahwa lama menderita tidak berhubungan dengan kualitas hidup Lansia penderita DM tipe 2 .

Lama menderita DM merupakan durasi waktu sejak awal didiagnosa sampai saat penelitian dilakukan. Responden yang lama menderita $\geq 10$ tahun memiliki efikasi diri yang baik, karena semakin lama seseorang menderita maka berarti semakin lama kesempatan untuk belajar menghadapi masalah yang timbul terkait penyakitnya sehingga hal itulah yang bisa meningkatkan kualitas hidupnya dibanding seseorang yang menderita $<10$ tahun. Kualitas hidup yang rendah pada responden tidak hanya bergantung dari lamanya waktu menderita penyakit DM tetapi juga dipengaruhi oleh kondisi ekonomi. Meskipun telah lama menderita jika tidak memiliki cukup uang untuk perawatan dirinya 
maka akan menurunkan kualitas hidup.

\section{KESIMPULAN}

Berdasarkan hasil penelitian dapat disimpulkan bahwa jenis kelamin, tingkat pendidikan, status pekerjaan, status ekonomi, dan lama menderita DM memiliki hubungan yang signifikan dengan kualitas hidup penderita diabetes mellitus di Kabupaten Gorontalo. Sedangkan variabel umur tidak menunjukkan hubungan yang signifikan dengan kualitas hidup penderita diabetes mellitus di Kabupaten Gorontalo.

\section{SARAN}

Dalam upaya peningkatan kualitas hidup diabetes mellitus sebaiknya masyarakat yang menderita DM agar lebih aktif dalam mengikuti setiap program yang dilaksanakan oleh pihak pelayanan kesehatan. Para tenaga kesehatan juga harus memberikan perhatian penuh bagi para penderita terutama dalam hal peningkatan kualitas hidup dengan memperhatikan beberapa variabel dalam penelitian ini.

\section{UCAPAN TERIMA KASIH}

Terima kasih bagi semua anggota tim peneliti termasuk semua enumerator (Mahasiswa FKM Universitas Gorontalo) yang bersedia membantu dan bekerja sama sehingga penelitian ini dapat terlaksana dengan baik sampai tersusunnya laporan hasil penelitian dalam bentuk jurnal penelitian.

\section{DAFTAR PUSTAKA}

Badan Pusat Statistik (BPS). (2018). Status Pekerjaan

Dinas Kesehatan Kabupaten Gorontalo. (2017). Data Penderita Diabetes Melitus 3 Tahun Terakhir. Kabupaten Gorontalo

Dinas Kesehatan Provinsi Gorontalo (2014). Data penderita Diabetes Melitus di Provinsi Gorontalo. Provinsi Gorontalo

IDF (International Diabetes Ferderation). (2015). Diabetes Atlas Seven Edition.

Infodatin Pusat Data dan Informasi Kementrian Kesehatan RI. (2014). Situasi dan Analisis Diabetes.

Kementerian Kesehatan RI. (2018). Hasil Riset Kesehatan Dasar tahun 2018. Kemenkes RI : Jakarta.

Meidikayanti, W., Wahyuni, C. (2017). Hubungan Dukungan Keluarga dengan Kualtias Hidup Diabetes Melitus tipe II di Puskesmas Pademawu.

Ningtyas, D., Wahyudi, P., Prasetyowati, I. (2013). Analisis Kualitas Hidup Pasien Diabetes Melitus Tipe II di RSUD Bangil Kabupaten Pasuruan. Artikel Ilmiah , 1-7.

Retnowati, N., Satyabakti, P. (2015). Hubungan Dukungan Keluarga Dengan Kualitas Hidup Penderita Diabetes Melitus Di Puskesmas Tanah Kalikedinding. Jurnal Berkala Epidemiologi, Vol. 3, No.1, 57-68.

Sari, R. M., Thobari, J. A., \& Andayani, T. M. (2011). Evaluasi Kualitas Hidup Pasien Diabetes Melitus Tipe 2 Yang Di Terapi Rawat Jalan Dengan Anti Diabetik Oral Di RSUP Dr. SARDJITO. Jurnal Manajemen Dan Pelayanan Farmasi Vol. 1 No. 1 Maret 2011, 35-42. 
Setiyorini, E., Wulandari, N. (2017). Hubungan Lama Menderita dan Kejadian Komplikasi Dengan Kualitas Hidup Lansia Penderita Diabetes Melitus Tipe II. 75-82.

Siwiutami, F. (2017). Gambaran Kualitas Hidup Pada Penyandang Diabetes Melitus di Wilyah Puskesmas Purwosari Surakarta. Naskah Publikasi Program Studi
Keperawatan Fakultas Ilmu Kesehatan Universitas Muhamadiyah Surakarta.

Wahyuni, Y., Nursiswati, Ana., Anastastia. (2014) Kualitas Hidup berdasarakan Pasien Diabetes Melitus tipe II. 2534.

WHO (World Health Organitation) (2016) Global Report On Diabetes 